\title{
Blogging as a method of inquiry
}

Naomi Barnes n3.barnes@qut.edu.au

School of Teacher Education and Leadership, Queensland University of Technology

\begin{abstract}
:
This paper reconceptualises Richardson's writing as inquiry within blogging. Blogging invites the audience into the scholarly conversation in ways Richardson hoped for in her articulation of the method. This paper explores writing as a method of inquiry through the writing of a blog for the academic news service, The Conversation. The piece was about the author's personal experiences with school choice, written using expressivist composition techniques championed by Richardson. This paper extends the technique to consider a reader-writer assemblage theory of composition made possible through the technical capabilities of blog posts - hyperlinks to past scholarship and comments which prompt future scholarship. The paper also considers the potential for blogging as inquiry as a method which inspires both personal and academic transformative shifts.
\end{abstract}

Key words: Blogging, writing as a method of inquiry, reconceptualising collaboration

Blogging is an assemblage of loaded words, meanings, images, and politics which can set up relationships across time and space. The writers, the humans who are the creators of the online text, are both simultaneously human, machine and text. Cyborgic assemblages which take on a life of their own once "Publish" is clicked. Cyborgic text which co-functions in symbiosis, in sympathy but not necessarily in harmony. Blogging is an act of inquiry. Blogging, if the author of the text is willing and open, is an act of becoming (Deleuze \& Guattari, 1980/1987).

In this paper, I propose the functional capability of blogging also adds a new angle to writing as an inquiry method (Richardson \& St. Pierre, 2008). Blogging as inquiry is a method which challenges the notion that writing is a natural and linear process for composing text. Blogging as inquiry is liminal. When I blog I am simultaneously reader, writer and audience. While I am pre-writing, drafting, revising, and proof-reading I am all the while publishing. I pre-write by composing tweets citing/about the literature I am reading; I draft by blogging longer pieces inspired by those tweets and interactions with my audience-followers; I revise those ideas I blogged when comments come in about the blogs; I continuously proof-read and edit the blogs even as they are public - there is something different about knowing my words are out in public which prompts a different type of reading of my own work I cannot tap into when I write for editors. Online all the text I write is in public and each piece of text is an inquiry step to something else. I do not know what that something else necessarily is until I write it down. How 
my online audience reacts to my words generally takes me on a line of flight to elsewhere. Writing online is an act of publicly continuously and forever becoming as a scholar.

Through this paper, I want to inch blog writing further into conversations about writing, particularly writing as inquiry. I hesitate to situate this within a framework because to do so pins it down, limits its liminality. I see myself as a theoretical flaneur, a "restless, nomadic, unruly thinker [who settles] down for a while to explore a new terrain, building on...earlier adventures, and then picking up what was most worth keeping and moving on" (Soja, 1996). Nevertheless, blogging as inquiry is situated in the small but emerging field that claims all writing to be collaborative. St Pierre (2014) writes about her collaboration with scholars from the past in her sole-authored text. Similarly, Speedy (2012) collaborates with her surrounds and her interactions. Wegener (2014) writes of conversations she had with a fictitious character to make sense of her ethnographic writing. Over the past year I have been visiting with Richardson (1997), St. Pierre (2014), and Haraway (1992) and begun to build a Deleuzean assemblage (1980/1987) of what it means to be a scholar online. I have begun to write minor texts (Barnes, in press) Deleuze, Guattari \& Brinkley, 1983) within the academicwritingmachine (Henderson, Honan, \& Loch, 2016). I have learnt that I do not have to deliberately stand separate from the text, that there is an ethical as well as scholarly connection between: authors past, present and future, fiction and nonfiction; my communities and those I write into being by writing about them; editors and critical friends; the Academe; the writing machine, both Deleuzian and cyborgic.

When I blog as a method of inquiry I am reminded of Haraway's famous line "I'd rather be a cyborg than a goddess" (Haraway, 1991, p. 181). Blogging flattens my scholarship by making transparent that my thoughts do not exist in a vacuum. It connects my work in a more animated way than that produced in the A4 page, Gutenberg paradigm of printed, unclickable text. It connects me cybernetically to the people I read through hyperlinking to their work, and scholarship yet to come through the comment banks attached to the blogs and the sharing of them on social media. These cyber-textual-organic relationships have become just as important to me as face-to-face reading groups, time alone with a new book, and silence when I'm writing.

Writing is an assemblage of texts, space and time and each one I produce is a pit stop in my own continuous journey of always and forever becoming. (To riff a famous passage from Deleuze and Guattari (1980/1987)) Therefore, a blog has no object. As an assemblage, a blog is openly connected with other assemblages, cyborgic assemblages of the human connected though machines, through hyperlinks, platform hosts and comments. Blogging as inquiry can be an assemblage of theorists, a place to be a conceptual flaneur and explore ideas and decide which ones resonate and which ones to discard because, as St Pierre (Richardson \& St. Pierre, 2008) famously says, without those words appearing on the screen, I may not have ever known. The extension that comes with blogging is that the audience can help which means blogging opens up a scholar to criticism. This is both terrifying and invigorating but a step I believe would be welcome in the ethical assembling of scholarship. What will make blogging a practice accepted within twenty-first century methodology? What will make it an ethical creation?

This paper is situated within writing process theory as a way to respond to the critique of the logical positivist/empiricist, cognitive and representationalist Cartesian dualist modes of language. This method employs elements of expressivist composition theory, process composition theory, and the Deleuzean inspired reading-writing assemblage theory outlined by St Pierre (2014). Like Henderson, Honan, and Loch (2016), this paper seeks to deconstruct the academicwritingmachine and reconstruct it in another way. But blogging also adds a new perspective on the composition on writing online. The clickable capability of blogs has considerable ramifications for public and scholarly engagement with academic 
work. They can seamlessly become a part of Richardson's (2002) career long campaign to validate alternative forms of academic writing, which are more engaging and reach wider audiences. Blogs can be used to present knowledge in traditional ways, but to do so is to not understand the full wonder of this technology which breaks with the Gutenberg project. Blogs are continuous without page breaks, they have texts in the margins. The functional capability of blogging, both personal, media, and academic blogs, provides opportunity for the writer to link in their influences and [usually] allows the audience to comment on the text offered by the author. In effect, a blog in its physical materiality is a collaboration between the past, present and future: the thinkers who went before are hyperlinked to the blog - smoothly inserted into the conversation by the click of a link, rather than found via the clumsiness of citations and reference lists. The reader of a blog can also force their way into the conversation through the comments section. Platforms such as Medium even allow readers to highlight and share their favourite quotations with their social media network, and Medium records where this has happened and where the blog author's words have gone. By being mindful of the composition techniques of blogging, a scholar invites the audience (both past and present) in to collaborate over what ideas continue forward, what needs further work and what needs rethinking (Bozalek \& Zembylas, 2017). Blogging as inquiry "begins as it ends, in the middle" (Deleuze \& Parnet, 2002 cited in Wyatt \& Gale, 2012, p. 345). It is fundamentally about learning and inviting others in to extend and challenge the ideas on the screen. It is a method where people assemble an idea together in a cyber-text-organic collaboration. I take portions of texts from others and hermeneutically expand on it; others take pieces of my text and assemble something new in another part of the Internet. If this method is conducted ethically, acknowledging the politics of the theoretical through hyperlinking, the scholarship lays itself out as a networked cyborgic, continuously becoming composition.

Ethical blogging also considers the effect and affect our words have on the worlds we write about because the construction of any text can be violent (Ahmed, 2017). When I blog I continuously write myself into existence and the times, spaces, and places I write about. These worlds are not mine alone. They are a collaboration between myself and my influences both fiction and non-fiction, fact and falsehood, history, and memory. They are a collaboration with my informants whose world views speak into mine. They are a collaboration with my audience who are deliberately invited in through the technical and expressivist composition of my blogs. They are a collaboration with Word Press and Internet providers who provide the platform on which I work. There is no singular entity responsible for the text that sits on the screen. There is no romance in blogging, it is more of a science fiction engaged in giving life to something more monstrous. The construction of a blog on the screen is not neat and tidy. There is no clear consensus between the parts of a blog and in an online space there is no obligation to have a harmonious collective will. Blogging can be both frightening and seductive. To know that I am being read makes blogging quite contagious.

Through the following I explain blogging as inquiry through one of my very public blogging experiences. I offer a deconstructed explanation of the process I underwent - my unravelling of my mangled lifeworld to fit into the linear-Gutenbergesque-paper-publication machine world. Each experience described below was layered on top of and through each other, the consequences of which I am still infected by today.

\section{Scholarship present: Blogging as a writer}

Writing is not just something that I do separate from my life. Writing comes from my experiences. My personal and private experiences inspire and fold into what I choose to write about. I came to blogging through my discomfort with the Cartesian rift and my loneliness in the solitary confines of my doctorate 
(Wyatt \& Gale, 2012). Whilst writing my doctorate dissertation, my advisors asked me to remove the "personal" from the text. I wondered how I could explain my decision making about my method without the personal, as my choices revolved around fitting my study in with the birth of my first child. I made my dissertation choices because of my personal circumstances, not despite them. I turned to blogging to tell my personal stories; about how writing a dissertation was like being pregnant. The blog became reasonably popular amongst other mothers writing their own dissertations and I have continued to keep a blog ever since. My current blog records my turbulent romance with the Academe as I navigate early career academia. While my dissertation experiences are a key part of this writerly assemblage that is by body (Ahmed, 2017), blogs have become the assemblage of the scholarship that now interests me.

As I write blogs, I became grounded in expressivist composition techniques (St. Pierre, 2014), particularly those modelled by Richardson (1997), who's work came to me as a relief from my struggle with the divide between traditional scholarly and personal writing. Like Richardson's (2002) writing, my blogging always situated myself in time and space and I always choose personal narration framed around personal reflexivity. In this section, I will deconstruct my approach to writing a blog, aligning myself to the Derridean (1982) project of disclosing writing practices to disclose forms of power.

The blogging experience I refer to here was no different. The blog post, an assemblage of both personal and professional circumstances, I wrote for The Conversation, an academic news service, whose vision is to write expert articles with journalistic flair to create a link between the Academy and policy makers. I contextualised myself in the Australian school choice debate which sees tension between those who choose private/independent/religious schools and those who send their children to state funded schooling. The blog was written to advocate for the importance of supporting a local school because anecdotal stories shared with me in my local parks suggested that many local families were choosing to not send their children to the local school. Faced with sending my eldest daughter to school for the first time I was intent on the local government school for various reasons made explicit in the article (Barnes, 2015); however, whenever I discussed my choice in parks with other parents, my local state school was not under consideration, even from families who lived very close. Doubt set in and I began to question my choice and make emotional judgements about other's motivations for not choosing it. In fact, the process was sensational; I became angry and I felt it on my skin (Ahmed, 2017). I have decided here to not write the nastiness of those interactions into this paper as I don't want to write my local area into being as something it probably is not, especially through the eyes of white [hot] liberal righteous anger I felt. The process of writing the blog was an assemblage of my anger, my belief in state schooling, and an exploration and an affirmation of my beliefs.

It was also plugged into my professional life as a social media researcher. At the time, I was embedded in the personal school choice process, I was working on a project at my university on academic blogging. I was hired as an independent research associate to look at the literature and online processes that academics were using to distribute and discuss their research. By reading about blogs, helping academics write them, and writing them myself, I began to realise that online spaces like The Conversation could function within academic publication processes the same way a conference can: instead of using a blog to discuss research, use it to further develop research. Blogging also embraces a style of writing uncommon, though not unheard of, in academic literature. Blogs provide an emerging/alternative genre for continuing to question how academic scholars engage with their audience or open up new audiences. The commentary or forum capability on a blog and the vision of The Conversation also encourage non-academics to engage with academic ideas and thinking. In the comments section of an online forum a scholarly (or not so scholarly) exchange can be had in a timely manner because the usual gatekeepers (like extended publication timelines and toll access) that 
protract engagement with knowledge are bypassed. I planned to use the experience as an inquiry into academic media to better advise the academics who were interested in moving into the blogging space as a part of their practice.

The writing of the blog was in mode and medium an act of academic activism, though at the time I felt it was social justice activism in the field of school choice. By sharing my story on social media I was "coloring outside the lines" (Richardson, 2002, p. 414) of traditional academic notions of knowledge representation by crafting the blog for both academic and non-academic audiences. In a blog, an academic gives up what Barthes calls "the ownership of the means of enunciation (cited in Shapiro, 1985-6, p. 195). By using expressivist composition techniques, I lifted the veil of privileged truth and in turn intersected the claims to power which come with that truth. I situated the blog in my local community by describing the demography of my suburb, not through statistics and graphs, but through narrative devices generally ascribed to setting in fiction writing. I wrote my community into the blog and in doing so wrote it in part into existence for the approximately 30,000 people who read it. By deliberately situating myself and my experience into the text, I worked to demystify the authority claims usually associated with academia.

By writing autobiographically, I could insert emotion generally absent from academic writing (Ahmed, 2017). While I was not aware of it at the time, I was accidentally utilizing expressivist composition techniques pioneered in the social sciences by qualitative researchers like Richardson (2012), St Pierre and Pillow (2002) who worked to provoked reactions from their audiences by working the fringes of academic genre. Part of continuously assembling my academic identity and research involves coming across scholars who justify what I want to do, rather than give me permission in advance. By blogging, people have hyperlinked me to the scholars, and I have clicked through their scholarly journeys in a networked literature adventure.

Blogging this way resists the Cartesian bounded genre, is explicit in its construction using autobio/ethnography, and invites the audience to participate in the knowledge making process (Richardson, 1993). The blog on school choice was an assemblage of new and future theories about the role of blogging in academia, my frustration at playground conversations, and an experiment to see what would happen. It very quickly became a transformative process for myself, both personally and how I saw the role of online scholarship.

\section{Scholarship future: Blogging as an audience}

I experience a rush of adrenaline when I see an email or Twitter notification indicating one of my readers has cared enough about what I wrote to respond with their own contribution. Sometimes those readers write a blog of their own to respond in some way to a point in what I wrote. These interactions are lovely and give me a sense that my ideas are worth exploring further and that adventure awaits. Sometimes the interactions are brutal. I have been trolled - called names, had my parenting questioned, and told that my work is self-indulgent. Fortunately, at this point I have not experienced the rape threats or defamation many online writers have experienced, but keeping the possibility as a part of this blogging as inquiry assemblage is vital as I move forward. While I do not want to excuse bad behaviour online, the reaction I get to my blogging has helped me inquire deeper into how I compose my text to provoke a more generous response, while still pushing the boundaries of thought about education.

As I shape my blog, my blogging shapes me. Through my readier-writer-becoming I have become more grounded in my world view: I have more understanding of what I believe, what I will tolerate, and what I 
will agitate against. A large part of that is the push back of my audience. Blogging means the lack of control a writer has over their audience is more apparent but simultaneously allows a writer to consider the needs of the audience. Through blogging a writer can get a better idea of what the audience thinks, folding that into what the author thinks. The piece I wrote for The Conversation is an example of my experimentation of blogging in a very public space as but it also sent me on lines of flight (Deleuze and Guattari 1980/1987) into education issues by reading my audience.

I was quite excited to have a piece published in The Conversation and eagerly looked at the reaction to the post after it went live. To my despair, the initial reactions were negative. I tried to respond to the comments, thanking the writer of the comment for their feedback but soon the comments were coming so quickly I could not keep up. I decided to enact a technique that Richardson (1993) used, allowing the audience to engage with the research without interference from the provocateur and see how the discussion developed. I decided to pick over the ruins (St Pierre \& Pillow, 2002) of my self-righteousness at a later date.

The audience reaction to the blog was a transformative process. Most the comments were full of support and transient stories of others. If the blog and the comments are read together, it may, to the reader, seem like a lovely meandering story of the multiplicity of positive stories which make up state schooling. However, it is not that. There was a reasonable amount of push back from the audience about my stance which I have seriously taken into consideration as I continue my parenting and scholarly journey.

Through the blog for The Conversation, I was made more aware of my class and my whiteness and the loaded nature of the word "choice". There was a connection between my class and my choice is what determines my action on this occasion; that my position of privilege blinded me to the reality of those outside of my economic bracket. I was reminded of government schools with leaking toilets, lack of temperature control and asbestos; that the enthusiasm of the teachers and support of the parents is often all that a school has to inspire their students and if either of these is lacking, the cultural reproduction of disadvantage is likely to continue. I was challenged as to whether I would consider such a school if that was my local school.

As comments on The Conversation blog came in I began to tweak my thinking. My mind is flexible trying to compromise and understand. I read the comments and wrote more online and off, I think, I synthesise, and I wrestle with ideas. Each blog is an archive of those thoughts and links to what I have read. As I continue to read and write, I revisit and re-read what I wrote - extrapolating, expanding, revising, discussing. It is an iterative process.

My organic existence is experience: a to-and-fro between creature and milieu. I act upon things and they act upon me. I receive impressions, but my mind gives them colour, shape significance. These prompt some reflex, habit or choice, which invites response form the world (Young, 2016, 11-12).

My writing, my blogging is a record of my always and forever becoming as a scholar, a reader, a mother, a community member, partner, sister, aunt, teacher.

\section{Scholarship past: Blogging as a reader}

While I read extensively before writing the blog for The Conversation it was the audience reaction to the piece which jolted me out of my complacency as a scholar who could provide findings in neat packages. 
The comments were so raw and intimate at times that I began a reading journey to try to honour them in their messiness. It is this desire that has taken me to the writing of new scholars (to me).

Often the reader is forgotten in an author-centric world of literary theory. We talk about Mary Wollstonecraft Shelley more than we talk about those who read her. The reason blogging as inquiry rests, for now, in the post qualitative paradigm is because to be a part of it is to know who is reading Deleuze and Guatarri, Barad, and Derrida and recognize, in turn, who is reading St. Pierre, Lather, and Richardson. The cyborgic textual-organic connection of reading is there for all readers to see. Young (2016) explains, concentration on authorship simplifies the text. It becomes about who the person is who wrote the words, and dismisses the bodily experiences those words create in the reader. It makes sense that these authors and others are cherished because they can invoke feelings that make us want to go back to again and again. To read and re-read. Plunging deeper into the words. Therefore, the writer to reader relationship needs to be cognizant of that connection.

When the focus is also squarely on the reader, the text continues, for some, for millennia; forming and reforming as new interpretations and dogmas are laid over and resisted (Young, 2016). Ahmed (2017) and many other feminist scholars of colour have even made this relationship an act of activism by choosing to only connect feminist and/or women of colour to their texts. This act of reading politically works to bring diversity into a homogenous field. In the future, I would like to explore such theoretical activism, but for now, the citations I have chosen for this paper are about honoring those who I have read to get me here, just as much as it is about blogging as a method of inquiry. This present paper is plugged into a cherished St. Pierre (2014) paper. It is cherished because in the reading of it, I began to see blogging in a new and exciting way. The paper spoke into my blogging soul. Much of my blogging diffracts off other authors words, whether they are scholars, like St Pierre, or social media conversations had around the text I have composed. Theories of reading, according to St Pierre, are hardly ever included in theories of writing but, with blogging, to avoid reading is to avoid your audience because the comments come in and remind you they exist.

Since writing the blog for The Conversation, my personal and professional blogging has become a reading management system. Each blog is an archive of the citations and thoughts I have about messy scholarship. For me, scholarship begins with broadcasting what I am reading on Twitter (tweeting). I write direct quotes and paraphrased thoughts straight from the literature as I read it. If I like a paper enough, I will hermeneutically blog about it. In fact, one of the reviewers of this paper asked me what I meant by "(reflexive/diffractive people)". I knew in the reread-write that rather than being "glib" I had, in fact, missed a citation for a journal paper I had blogged about on melding of reflexivity and diffraction. It was a simple matter of going to the blog to remember who the "people" were and inserting the citation. This interaction became an assemblage of past (read), present (this paper) and future (the reviewer) scholarship that has produced this paper. While the authorship is mine, it belongs to those who made it. My name is just the cherry on top.

Just as in the process of writing for publication and interacting with reviewers and editors, blogging makes transparent that process. I interact with my audience/followers over their questions and additions to what I have tweeted. I then continue to read the literature through those online conversations. I read, tweet, discuss, repeat until I need to write more than 140 characters to synthesise my thinking, expand on an idea that is percolating, try to answer a question I couldn't. I assemble those words (tweets, citations, discussions, questions) I have on and offline into a blog where the process continues, just with a larger number of characters. As the size of the idea expands, so does the text. I blog for myself and when read that my audience has responded positively I submit a blog to a less 
intimate and supportive audience (news service or academic blog). Read-write-discuss-read-repeat. Blogging as inquiry. Collaborating as inquiry (Wyatt, et al., 2104). Blogging as becoming.

\section{Collaboration as inquiry}

Except for a few, "the writing that appears in academic journals often appears as a seamless uninterrupted stream of academic thought" (Speedy, 2013, p. 351). Writers are often silent on the collaborations that made them. Those they have cited are there as in the academic tradition, but those that have made them are often absent. The literature they read growing up, the book on their bedside table and the story in their kindle. Likewise, the conversations they have had in hallways, cafes, bars, and in the case of this paper, online are absent, but present. If no textual staging is innocent, then why not deliberately employ the politics of communication as an act of activism within the production of knowledge? In writing this paper, I have disclosed my writing practices as read through the medium of blogging. In doing so, I disclose the power the texts enact. The difference between this paper and a blog is that a blog warmly invites the audience to continue the deconstruction of the knowledge through the capability of the comments. In a blog the reader can become an immediate agent in the continued construction of knowledge. But it doesn't have to be that way. Traditional paper journals now reside primarily online. The ability for scholars to directly engage with their audience or for readers to discuss scholarship without the restrictions of time and space is becoming more of a reality. As such, the capability that blogging allows should be considered closely in the development of writing and composition theory.

Blogging as inquiry has made me. It has caused me to not be just a singularity or even a multiple. Blogging as inquiry has made me a multiplicity or "a simultaneity of 'stories-so-far'" (Massey, 2005, p. 9). To read just one of my blogs is to know only a part of me, but a whole part of me in that moment of time and space. My blog has no brand or social media strategy. I write about my life, my thinking, my hope for the future. I write my struggle with my world that seems to lack so much hope into existence at the same time as trying to solve that struggle. My blogging is a map, not a snapshot.

This paper has proposed a reconceptualization of Richardson's (1994) - and later Richardson and St Pierre's, (2008) - writing as a method of inquiry for the digital world. By blogging as a method of inquiry the process of personal discovery and academic activism which underscores the Richardson's version of the method is amplified in the digital world. The relationship between the writer and the reader is much more intimate than through traditional academic publications. Blogging as inquiry means letting go of "I" and embracing "we". It can become a part of the ethical dialogues Strumm (2014) writes about "the hospitality of reception and the reciprocity of response" (p. 385). Blogging is communal; I continuously am a record of my becoming, linking to the becoming of others. Furthermore, the power over the production of knowledge so long corralled by the academicwritingmachine (Henderson, et al., 2016) is intersected. Blogging is open access, it can employ various modes and genres of communication, and it invites the audience in to be an active part of the process of knowledge making. As such blogging as a method of inquiry is also blogging as a method of collaboration and collaboration as a method of inquiry.

I am immensely grateful to Dr. Stewart Riddle and the anonymous reviewer whose comments greatly improved the manuscript. I would also like to acknowledge the encouragement given by Dr. Helen Kara and Dr. Janet Salmons who critiqued the initial abstract. 


\section{References}

Ahmed, S. (2017). Living a Feminist Life. Duke University Press. https://doi.org/10.1215/9780822373377

Barnes, N. (2015). Why l'm choosing the local state school - even though it doesn't have all the bells and whistles. In The Conversation AU. 9 October 2015. https://theconversation.com/why-imchoosing-the-local-state-school-even-though-it-doesnt-have-all-the-bells-and-whistles-48154

Barnes, N. (in press). Composing with the Chthulucene: Desiring a minor literature. In S. Riddle, E. Honan, and D. Bright (eds). Writing with Deleuze in the Academy: Creating Monsters. Springer.

Bozalek, V., \& Zembylas, M. (2017). Diffraction or reflection? Sketching the contours of two methodologies in educational research. International Journal of Qualitative Studies in Education, 30(2), 111-127. https://doi.org/10.1080/09518398.2016.1201166

Deleuze, G., \& Guattari, F. (1987). A thousand plateaus. (Brian Massumi, Trans) Minneapolis: University of Minnesota Press. (Original work published 1980).

Deleuze, G., Guattari, F., \& Brinkley, R. (1983). What Is a Minor Literature? Mississippi Review, 11(3), 1333

Derrida, J. (1982). Margins of philosophy. University of Chicago Press.

Haraway, D. (1992). The Promises of Monsters: A Regenerative Politics of Inappropriate/d Others in Cultural Studies. Cultural Studies. New York: Routledge.

Haraway, D. (1991). "The Actors are cyborg, nature is coyote, and the geography is elsewhere: postscript to 'Cyborgs at Large'” in C. Penley and A. Ross (eds.) Technoculture. Mineapolis: University of Minnesota Press.

Henderson, L., Honan, E., \& Loch, S. (2016). The production of the academicwritingmachine. Reconceptualizing Educational Research Methodology, 7(2), 4-18. https://doi.org/10.7577/rerm.1838

Massey, D. (2005). For space. London: Sage.

Richardson, L. (1993). Poetics, dramatics, and transgressive validity: The case of the skipped line. The Sociological Quarterly, 34(4), 695-710. https://doi.org/10.1111/j.1533-8525.1993.tb00113.x

Richardson, L. (1994). Writing: A method of inquiry. In N. Denzin and Y. Lincoln (Eds). Handbook of qualitative research. Thousand Oaks, Ca: Sage Publishing. 516-529.

Richardson, L. (1997). Fields of play: Constructing an academic life. Rutgers University Press.

Richardson, L. (2002). Writing sociology. Cultural Studies $\leftrightarrow$ Critical Methodologies, 2(3), 414-422.

Richardson, L. (2012). My Story and I'm Sticking to it-Until I Revise it. Blue Ribbon Papers: Blue Ribbon Papers: Behind the Professional Mask: The Self-Revelations of Leading Symbolic Interactionists, 38, 215-238. https://doi.org/10.1108/S0163-2396(2012)0000038013

Richardson, L., \& St Pierre, E. (2008). Writing: A method of inquiry. In N. Denzin and Y. Lincoln (Eds). Collecting and interpreting qualitative materials: Volume 3 of Handbook of Qualitative Research Methods. Thousand Oaks, Ca: Sage Publishing. 473-499.

Shapiro, M. J. (1985). Metaphor in the Philosophy of the Social Sciences. Cultural Critique, (2), 191-214. https://doi.org/10.2307/1354206

Soja, E. W. (1996). Thirdspace: Journeys to Los Angeles and other real-and-imagined places. Cambridge, Massachusetts: Blackwell.

Speedy, J. (2013). Collaborative writing and ethical know-how: Movements within the space around scholarship, the academy and the social research imaginary. International Review of Qualitative Research, 5(4), 349-356. https://doi.org/10.1525/irar.2012.5.4.349

St. Pierre, E. A. \& Pillow, W. (Eds.). (2002). Working the ruins: Feminist poststructural theory and methods in education. Routledge.

St. Pierre, E. A. (2014). An always already absent collaboration. Cultural Studies $\leftrightarrow$ Critical Methodologies, 14(4), 374-379. https://doi.org/10.1177/1532708614530309 
Stumm, B. (2014). The Intersubjective Ethics of Dialogue: Practicing Reciprocal Reception and Responsibility in Stolen Life-The Journey of a Cree Woman. Cultural Studies $\leftrightarrow$ Critical Methodologies, 14(4), 385-395. https://doi.org/10.1177/1532708614530311

Wegener, C. (2014). Writing with Phineas: How a fictional character from AS Byatt helped me turn my ethnographic data into research texts. Cultural Studies $\leftrightarrow$ Critical Methodologies, 14(4), 351-360. https://doi.org/10.1177/1532708614530306

Wyatt, J., \& Gale, K. (2012). Singularities and Multiplicities. A Preface to the Special Issue on Collaborative Writing. International Review of Qualitative Research, 5(4), 345-347.

Wyatt, J., Gale, K., Gannon, S., Davies, B., Denzin, N. K., \& Pierre, E. A. S. (2014). Deleuze and Collaborative Writing Responding to/With “JKSB". Cultural Studies $\leftrightarrow$ Critical Methodologies, 14(4), 407-416. https://doi.org/10.1177/1532708614530313

Young, D. (2016) The art of reading. Melbourne: Melbourne University Press. 